\title{
Aplikasi Pakan Kaya Karotenoid Hasil Fusi ProtoplasmIntergenera Dunaliella salina dan Chlorella vulgaris pada Udang Windu (Penaeus monodon F.) Stadia PL-20 Di Desa Asempapan, Pati, Jawa Tengah
}

\author{
Novia Rahmawati ${ }^{1}$, Muhammad Zainuri ${ }^{2}$ dan Hermin Pancasakti Kusumaningrum ${ }^{1}$ \\ 1. Jurusan Biologi, Fakultas Sains dan Matematika, Universitas Diponegoro \\ 2. Fakultas Perikanan dan Ilmu Kelautan, Universitas Diponegoro, Kampus Tembalang, Semarang 50275 \\ Telp/Fax. 024-7474698 \\ email: rahma.noviasan@gmail.com
}

\begin{abstract}
Dunaliella salina and Chlorella vulgaris is a natural feed microalgae with high carotenoid content that can be increased using protoplast fusion technique. Protoplast fusion as one of the application fields of genetic engineering is a method for obtaining recombinant with the desired properties and profitable in a short time. This study aimed to see the effect of the addition of carotenoid-rich feed results from protoplast fusion recombinant $D$. salina and $C$. vulgaris on the survival rate and weight of shrimp post larvae. Mixed fusion results feed and artificial feed needed for the growth of post-larval shrimp, moulting and skin pigmentation. The results showed that the recombinant from protoplast fusion intergenera $D$. salina and C. vulgaris contains carotenoid pigments higher, reaching $124.6 \mathrm{mg} / \mathrm{g}$ bks from the second parent, namely D. salina reached $101.83 \mathrm{mg} / \mathrm{g}$ bks, while C. vulgaris $97.18 \mathrm{ug} / \mathrm{g}$ bks. Feed manufacturing is done by mixing pellets and $80-100 \times 10^{3}$ cells per $0.0225 \mathrm{~g}$ of feed. Application of feed carried on Penaeus monodon F. (tiger prawn) stadia PL-20 for a month. The results of weight measurements showed the highest prawn post larvae reached at artificial feeding plus recombinant protoplast fusion results intergenera $D$. salina and $C$. vulgaris and was able to raise the level of post-larval shrimp survival rate reached $88 \%$.
\end{abstract}

Keywords: D. salina, C. vulgaris, Protoplast Fusion, Carotenoid, Penaeus monodon F.

\begin{abstract}
Abstrak
Dunaliella salina dan Chlorella vulgaris merupakan mikroalga pakan alami dengan kandungan karotenoid tinggi yang dapat ditingkatkan kandungannya menggunakan teknik fusi protoplas. Fusi protoplas sebagai salah satu aplikasi bidang rekayasa genetika merupakan suatu metode untuk memperoleh rekombinan dengan sifat-sifat yang dikehendaki dan menguntungkan dalam waktu singkat. Penelitian ini bertujuan untuk melihat pengaruh penambahan pakan kaya karotenoid dari rekombinan hasil fusi protoplas $D$. salina dan $C$. vulgaris terhadap tingkat kelulushidupan dan bobot post larva udang. Campuran pakan hasil fusi dan pakan buatan dibutuhkan post larva udang untuk pertumbuhan, pigmentasi dan pergantian kulit. Hasil menunjukkan bahwa rekombinan hasil fusi protoplas intergenera $D$. salina dan $C$. vulgaris mengandung pigmen karotenoid lebih tinggi yaitu mencapai 124,6 g/g bks dari kedua induknya, yaitu $D$. salina mencapai 101,83 g/g bks, sedangkan $C$. vulgaris 97,18 g/g bks. Pembuatan pakan dilakukan dengan pencampuran pelet dan sel rekombinan sebanyak $80-100 \times 10^{3}$ sel per $0,0225 \mathrm{~g}$ pakan. Aplikasi pakan dilakukan pada Penaeus monodon F. (udang windu) stadia PL-20 selama satu bulan. Hasil pengukuran menunjukkan pertambahan berat post larva udang tertinggi dicapai pada pemberian pakan buatan ditambah rekombinan hasil fusi protoplas intergenera $D$. salina dan $C$. vulgaris dan mampu meningkatkan tingkat kelulushidupan post larva udang mencapai $88 \%$.
\end{abstract}

Kata Kunci $\quad$ : D. salina, C. vulgaris, Fusi Protoplas, Karotenoid, Penaeus monodon F.

\section{PENDAHULUAN}

Udang merupakan salah satu primadona komoditas perikanan yang populer dan memiliki nilai tinggi. Produksi udang windu mengalami penurunan sebesar 1,85 persen setiap tahunnya. Turunnya produksi udang windu akibat adanya penyakit yang menyerang udang windu, apalagi windu termasuk komoditas yang rentan terhadap 
penyakit (Kementerian Kelauatan dan Perikanan, 2011).

Fase pertumbuhan udang yang mudah terserang penyakit pada udang adalah tahap post larva. Pertumbuhan dan ketahanan penyakit pada larva udang sangat ditentukan oleh pakan yang diberikan. Peningkatan kandungan nutrisi dari pakan alami akan berpengaruh pada kualitas larva udang windu sehingga kelangsungan hidupnya dapat meningkat (Mujiman \& Suyanto, 2003).

Salah satu aplikasi dalam bidang rekayasa genetik adalah rekombinasi dengan metode fusi protoplas. Fusi protoplas menawarkan keunggulan karena prosedurnya relatif lebih mudah dan ekonomis dibandingkan dengan yang lain dan segera menghasilkan rekombinan baru yang dikehendaki untuk perbaikan mutu dan sifat dalam waktu yang singkat (Zainuri et al., 2009).

$D$. salina dan $C$. vulgaris merupakan mikroalga dengan kandungan karotenoid total yang tinggi yaitu mencapai $6000-8000 \mathrm{~g} / \mathrm{g}$. Udang merupakan hewan budidaya yang tidak dapat mensintesis vitamin A. Terkait dengan hal itu, larva udang membutuhkan pakan dengan kandungan karotenoid yang cukup untuk kelangsungan hidupnya. Karotenoid adalah pigmen organik pro-vitamin A yang terdapat secara alamiah pada organisme fotosintetik, termasuk $D$. salina dan $C$. vulgaris.

Daerah Pati Jawa Tengah selama ini dikenal sebagai salah satu produsen benih udang unggul yang penjualannya untuk memenuhi permintaan di wilayah Jawa Tengah. Petani tambak udang windu di Pati, Jawa Tengah umumnya hanya memberikan pakan buatan saja setelah udang tumbuh pada tahapan post larva. Masalah utama yang dihadapi petani tambak udang di daerah tersebut adalah kematian benih yang cukup banyak yaitu sekitar $20 \%$.

Sejauh ini belum pernah diupayakan pemberian pakan yang terdiri dari beberapa karotenoid penting hasil penggabungan karotenoid yang dimiliki $D$. salina dan $C$. vulgaris hasil teknik fusi protoplas. Penelitian yang akan dilakukan ingin memberikan pakan alami kaya karotenoid untuk larva udang dari rekombinan hasil fusi protoplas, dengan harapan rekombinan unggul kaya karotenoid tersebut bila dikonsumsi larva udang dapat meningkatkan kelulushidupan hidup post larva udang.

\section{BAHAN DAN METODE Bahan Penelitian}

Bahan penelitian yaitu mikroalga $D$. salina media cair dan C. vulgaris media cair didapatkan dari Balai Besar Pengembangan Budidaya Air Payau (BBPBAP) Jepara, rekombinan hasil fusi protoplas intergenera $D$. salina dan $C$. vulgaris yang diperoleh dari penelitian Kerja Praktik Yohanes Chandrawijaya (2012), udang windu stadia PL-20, pupuk Walne, alkohol, spiritus, aquades steril, eter, sodium fosfat $0.1 \mathrm{~N}, \mathrm{NaOH}$ 0.5 N, Dimethyl Sulfoxide (DMSO), glass beads, methanol, pH stick.

\section{Produksi Pigmen Total}

a. Pembuatan kurva pertumbuhan dan kurva produksi pigmen

Medium starter sebanyak $5 \mathrm{~mL}$ yang diinokulasikan pada medium baru $100 \mathrm{~mL}$ (medium air laut steril yang ditambahkan dengan pupuk walne) dikultivasi selama 9 hari untuk pengukuran pertumbuhan dan produksi pigmen total. Biakan dikultivasi dengan aerator dengan kecepatan $180 \mathrm{rpm}$. Pengukuran pertumbuhan dan produksi pigmen total tersebut dilakukan setiap hari.

b. Pengukuran produksi pigmen dengan metode spektrofotometer (Sedmak et al., 1990).

Kultur D. salina dan C. vulgaris kontrol dan hasil fusi protoplas sebanyak $5 \mathrm{~mL}$ dimasukkan ke dalam tabung reaksi, kemudian disentrifugasi dengan kecepatan $3500 \mathrm{rpm}$ selama 15 menit. Pelet yang diperoleh ditambah dengan $0,1 \mathrm{~mL}$ sodium fosfat $(0.1 \mathrm{~N}) \mathrm{pH}$, glass beads, dan $1 \mathrm{~mL}$ DMSO yang telah dipanaskan hingga suhu $55^{\circ} \mathrm{C}$. Campuran divortex dan ditambah dengan 2,0 mL eter. Campuran dihomogenisasi dengan vortex selama 10 menit lalu disentrifugasi dengan kecepatan $3500 \mathrm{rpm}$ selama 10 menit. Dua fasa yang diperoleh dipisahkan, pigmen akan tercampur dengan eter pada fasa atas, diambil dengan pipet dan dimasukkan ke dalam tabung reaksi lain. Pigmen dipisahkan dari eter dengan cara evaporasi sampai kering. Eter yang telah menguap atau kering, ditambah dengan methanol $3 \mathrm{~mL}$ dan dipindahkan ke kuvet spektrofotometer untuk 
mendapatkan nilai absorbansinya dengan panjang gelombang $480 \mathrm{~nm}$ (Sedmak et al, 1990).

Pigmen total ditentukan dengan koefisien ekstinsi (extinction coefisient) $1 \%\left(E_{1 c m}^{1 \%}=2680\right)$ dengan formulasi sebagai berikut :

$$
\begin{aligned}
& X^{1}: \frac{(A-480)(V 1)}{\left(E_{1 c m}^{1 \%}\right)(V 2)} \times 10^{4} \\
& X: \frac{X^{1}}{P} \times 10^{3}
\end{aligned}
$$

dimana :

$X \quad$ : pigmen total yang dihasilkan $(\mu \mathrm{g} / \mathrm{g})$

$V 1 \quad$ : volume pelarut (metanol) $(\mathrm{ml})$

$V 2 \quad$ : volume larutan pigmen $(\mathrm{ml})$

A-480 : densitas optikal pada panjang gelombang 480

$E_{1 \mathrm{~cm}}{ }^{1 \%}$ : koefisien ekstinsi $1 \%=2680$

$P \quad$ : berat kering sel $(\mathrm{g} / \mathrm{ml})$

\section{Pembuatan Pakan dari Rekombinan Hasil Fusi} Protoplas Intergenera D. salina dan C. vulgaris

Pembuatan pakan dilakukan dengan pencampuran pelet (pakan pabrikan) dengan 80 $100 \times 10^{3}$ sel rekombinan D. salina per $0,0225 \mathrm{~g}$ pakan (untuk konsumsi larva udang 3 kali dalam sehari). Pembuatan pakan dikhususkan untuk udang tahap Post Larva (PL) yaitu dengan bobot tubuh larva udang $0,02 \mathrm{~g}-0,2 \mathrm{~g}$, jika diasumsikan bobot tubuh post larva udang yaitu $0,15 \mathrm{~g}$, maka diperoleh $0,0225 \mathrm{~g}$ dari $15 \%$ bobot tubuhnya.

\section{Pemberian Pakan}

Pemberian pakan pada benih udang dilakukan tiga kali dalam sehari, pagi, siang, sore hari selama satu bulan. Pemberian pakan dibagi menjadi empat perlakuan berbeda, yaitu:

- Kolam A, sebagai kontrol, larva udang diberi pakan (pelet) buatan pabrikan.

- Kolam B, larva udang diberi pakan buatan yang ditambah sel $D$. salina

- Kolam C, larva udang diberi pakan buatan yang ditambah sel $C$. vulgaris

- Kolam D, larva udang diberi pakan buatan yang ditambah sel rekombinan hasil fusi protoplas intergenera $D$. salina dan $C$. vulgaris

\section{Pengukuran Berat Udang}

Penimbangan berat larva udang PL-20 dilakukan setiap 2 kali dalam seminggu selama satu bulan dengan menggunakan neraca Sartorius dengan 3 kali ulangan.

\section{Pengukuran Tingkat Kelulushidupan}

Pengukuran tingkat kelulushidupan dilakukan terhadap jumlah post larva udang windu yang masih hidup pada akhir penelitian, dengan cara perhitungan sebagai berikut (Sunaryo, 2000):

$$
S R=\frac{N t}{N o} \times 100 \%
$$

Keterangan:

\section{SR : Survival Rate}

No : Jumlah post larva udang pada awal penelitian $\mathrm{Nt}$ : Jumlah post larva udang yang masih hidup di akhir penelitian

\section{HASIL DAN PEMBAHASAN}

Hasil pada (Gambar 1) menunjukkan bahwa terdapat perbedaan antara $D$. salina dan $C$. vulgaris murni dengan rekombinan hasil fusi protoplas keduanya. Rekombinan hasil fusi protoplas D. salina dan $C$. vulgaris memiliki bentuk sel yang tidak beraturan dan berukuran lebih besar $(7,5 \mathrm{~m}-12,5 \mathrm{~m})$ dari kedua induknya, yaitu $D$. salina $(2,5 \mathrm{~m}-7,5 \mathrm{~m})$ dan C. vulgaris $(3,75 \mathrm{~m}-12,5 \mathrm{~m})$. Bentuk yang paling sering muncul adalah rekombinan poliploidi dimana satu sel rekombinan akan memiliki lebih dari satu inti. Hal ini sejalan dengan hasil penelitian Hersugondo et al. (2010a,b), yang menunjukkan bahwa terjadinya rekombinan poliploidi akan menghasilkan satu sel rekombinan dengan inti lebih dari satu. Hal ini juga dijelaskan oleh Abosereh et al. (2007) yang menyatakan bahwa fusi protoplas akan menyebabkan terjadinya rekombinasi antara kromosom yang heterogen dalam sel diploid atau multiploid, kemudian akan terjadi pemisahan yang membentuk hanya satu genom. 

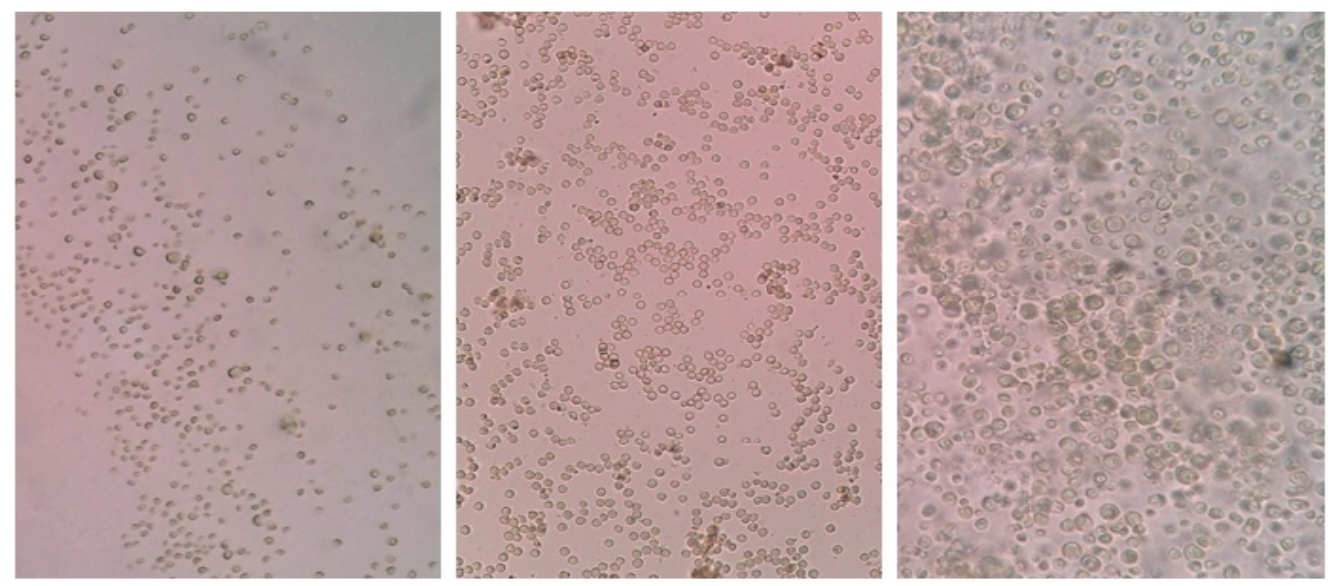

Gambar 1. Morfologi D. salina, C. vulgaris, dan rekombinan hasil fusi protoplas keduanya (perbesaran 400x) Ket= A: D. salina; B: C. vulgaris; C: Rekombinan hasil fusi protoplas D. salina dan $C$. vulgaris

Hasil pengamatan yang diperoleh selama 9 hari masa kultivasi, diperoleh pola pertumbuhan yaitu fase lag, fase logaritmik, fase stasioner dan fase menuju kematian. Rekombinan hasil fusi protoplas D. salina dengan C. vulgaris dan kedua induk memperlihatkan pola pertumbuhan yang serupa. Fase logaritmik $D$. salina dimulai pada kultivasi hari ke-3 dan fase stasioner pada hari ke7, sedangkan fase logaritmik $C$. vulgaris dimulai pada hari ke-3 dan fase stasioner pada hari ke-6. Rekombinan hasil fusi protoplas mulai memasuki fase logaritmik pada kultivasi hari ke-3 dan fase stasioner pada hari ke-7.

Hasil penelitian menunjukkan bahwa berat kering rekombinan hasil fusi protoplas intergenera
D. salina dan $C$. vulgaris yang memiliki massa lebih tinggi dibanding kultur murni kedua induk. Berat kering sel tertinggi $D$. salina dicapai pada hari kelima yaitu $8 \mathrm{~g} / \mathrm{L}$, sedangkan $C$. vulgaris dan rekombinan hasil fusi protoplas intergenera $D$. salina dan C. vulgaris mencapai berat kering sel tertinggi pada hari keenam, masing-masing 9,2 g/L dan $10 \mathrm{~g} / \mathrm{L}$. Hal ini mengindikasikan adanya pembentukan sel-sel ploidi sebagai hasil dari fusi protoplas sehingga menambah massa sel rekombinan hasil fusi protoplas.

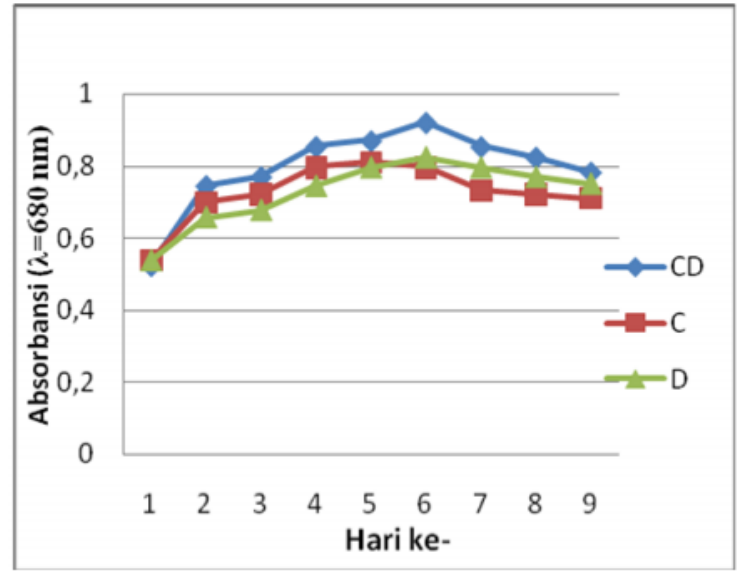

Gambar 2. Kurva pertumbuhan sel mikroalga

Ket. $\mathrm{CD}=$ Rekombinan hasil fusi protoplas intergenera C. vulgaris dan D. salina; $\mathrm{C}=$ C. vulgaris; $\mathrm{D}=D$. salina

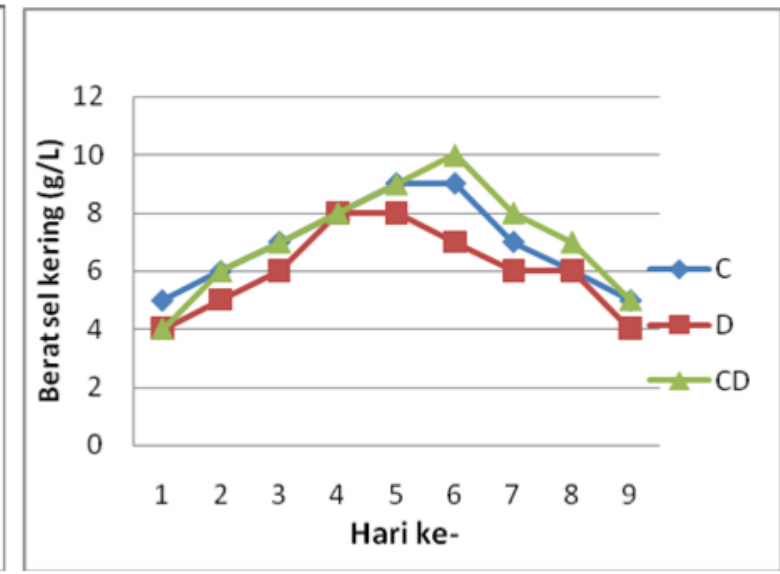

Gambar 3. Kurva Pertumbuhan Sel (Berat kering sel) Ket. $\mathrm{CD}=$ Rekombinan hasil fusi protoplas intergenera $C$. vulgaris dan D. salina; $\mathrm{C}=C$. vulgaris; $\mathrm{D}=D$. salina 
Pigmen total untuk rekombinan hasil fusi protoplas $D$. salina dan $C$. vulgaris lebih tinggi dibanding dengan pigmen yang dihasilkan oleh kedua induk. Pigmen total tertinggi $D$. salina mencapai $101,83 \mathrm{~g} / \mathrm{g}$ bks. Pigmen tertinggi $C$. vulgaris mencapai $97,18 \mathrm{~g} / \mathrm{g}$ bks. Pigmen total tertinggi rekombinan hasil fusi protoplas $D$. salina dan C. vulgaris mencapai $124,6 \mathrm{~g} / \mathrm{g}$ bks. Hal ini menunjukkan bahwa teknik fusi protoplas yang telah dilakukan pada $D$. salina dan $C$. vulgaris mampu meningkatkan produksi pigmen karotenoid yang dimulai pada saat fase stasioner. Penelitian serupa telah dilakukan sebelumnya pada khamir Phaffia rhodozyma dan teknik fusi protoplas terbukti meningkatkan kandungan karotenoid yaitu jenis astaxanthin hingga 2,03 kali lipat dibandingkan induk (Kusumaningrum et al., 2003).

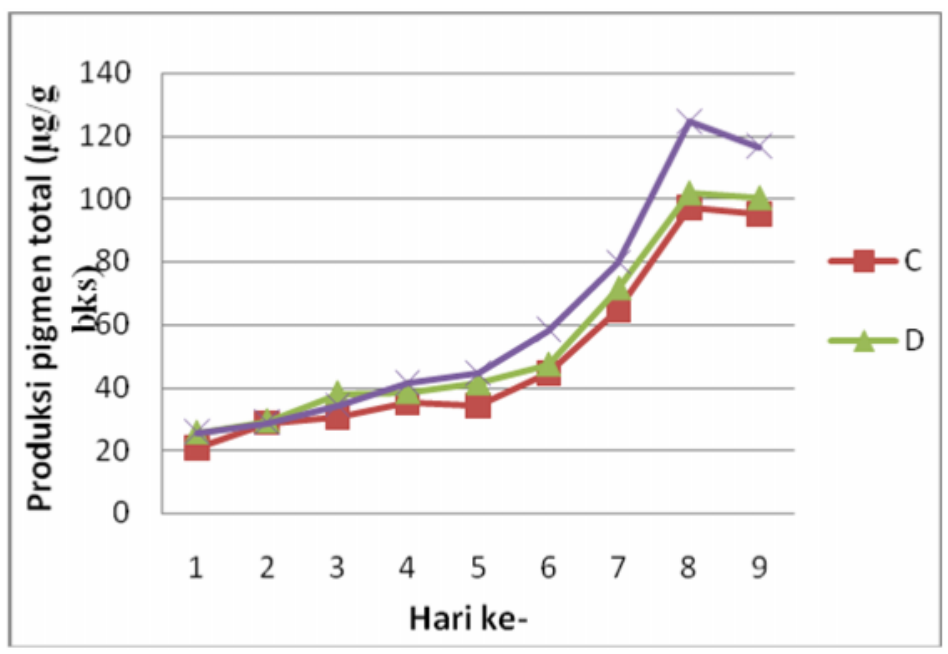

Gambar 4. Produksi pigmen total mikroalga

Ket. $\mathrm{C}=$ C. vulgaris $; \mathrm{D}=$ D. salina $; \mathrm{CD}=$ rekombinan hasil fusi protoplas $D$. salina $\operatorname{dan} C$. vulgaris

Hasil penelitian menunjukkan produksi pigmen karotenoid $D$. salina dan $C$. vulgaris serta hasil rekombinan fusi protoplas keduanya semakin meningkat sejalan dengan bertambahnya usia sel sampai menuju kematian, karena karotenoid merupakan metabolit sekunder yang dihasilkan setelah pertumbuhan menurun sampai menuju fase kematian. Hal ini sesuai dengan yang dikemukakan Agustini (2010) bahwa kadar karotenoid mikroalga secara umum meningkat seiring dengan bertambahnya waktu pertumbuhan. Pembentukan karotenoid tertinggi saat kultur mencapai fase stasioner. Fakta ini diduga berkaitan dengan usahanya untuk meningkatkan kemampuan penambatan cahaya pada fase stasioner, juga sebagai respon terhadap kenaikan salinitas medium saat fase stasioner, sedangkan Mendoza $e t$ al. (2008) menyatakan bahwa peningkatan total pigmen pada saat fase stasioner dikarenakan pigmen yang dihasilkan digunakan untuk pertahanan hidup sel saat nutrisi dalam medium mulai menipis.

Pemberian pakan buatan yang ditambahkan rekombinan hasil fusi protoplas intergenera $D$. salina dan $C$. vulgaris berdasarkan grafik di atas memperlihatkan kenaikan bobot tubuh larva udang sejak awal. Hasil analisis statistik menunjukkan terdapat perbedaan nyata antara pertumbuhan post larva udang sebagai kontrol (hanya diberikan pakan buatan/pabrikan saja), pertumbuhan post larva udang yang diberi pakan buatan dengan $D$. salina murni, pertumbuhan post larva udang yang diberi pakan buatan dengan $C$. vulgaris murni dan pertumbuhan post larva udang yang diberi pakan buatan dengan rekombinan hasil fusi protoplas $D$. salina dan C. vulgaris. 


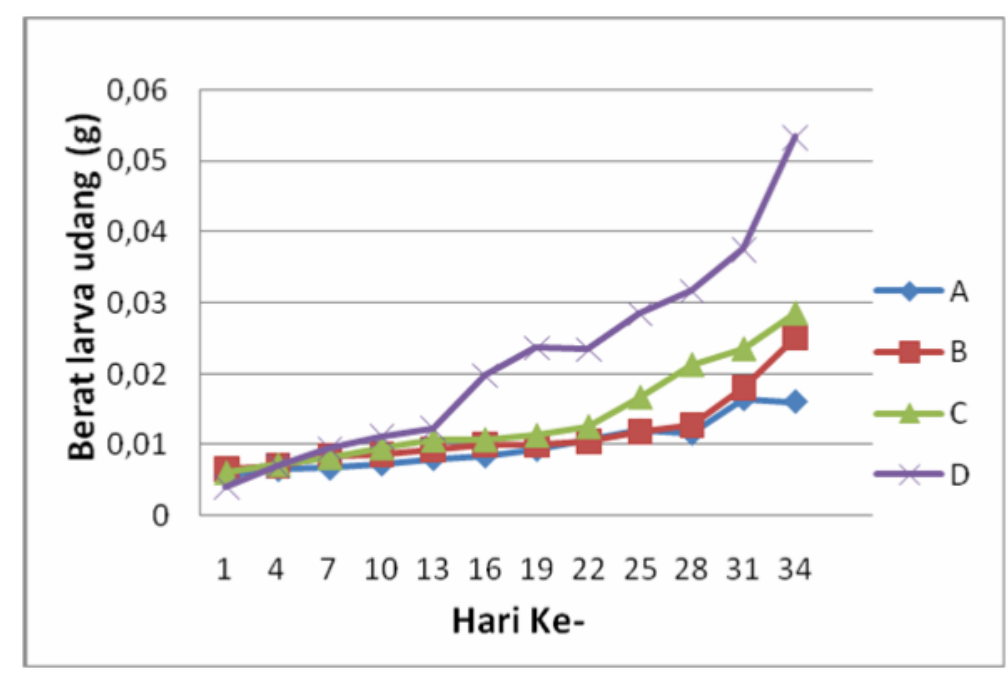

Gambar 5. Kurva pertumbuhan larva udang selama satu bulan Ket: A: kontrol; B: pelet $+D$. salina murni; C: pelet $+C$. vulgaris murni; D: pelet+rekombinan hasil fusi protplas D. salina dan C.vulgaris

Tahapan post larva ini udang cukup baik memanfaatkan nutrisi dalam pakan sehingga pertumbuhannya relatif cepat dan cenderung stabil. Hal ini sesuai dengan hasil penelitian sebelumnya yang dilakukan oleh Hersugondo et al. (2010a) yang menyatakan bahwa pemberian pakan $D$. salina akan meningkatkan pertumbuhan, survival, ketahanan terhadap penyakit dan daya tahan tubuh udang.

Kenaikan bobot yang terus berlangsung mengindikasikan bahwa pakan yang diberi penambahan rekombinan hasil fusi protoplas intergenera $D$. salina dan $C$. vulgaris telah menghasilkan komposisi nutrisi yang mendukung pertumbuhan dan kelangsungan hidup larva udang karena rekombinan yang dihasilkan terbukti mampu meningkatkan produksi karotenoid.

Tingkat kelulushidupan udang windu PL20 pada penelitian ini dengan pemberian pakan buatan ditambah dengan rekombinan hasil fusi protoplas intergenera $D$. salina dan $C$. vulgaris yaitu mencapai $88 \%$, sedangkan untuk kontrol (hanya diberi pakan buatan) $72 \%$, pakan buatan dengan tambahan $D$. salina yaitu $74,4 \%$, dan pakan buatan dengan tambahan $C$. vulgaris mencapai $80 \%$. Hasil menunjukkan bahwa pemberian pakan buatan dengan rekombinan hasil fusi protoplas intergenera $D$. salina dan $C$. vulgaris mampu meningkatkan kelulushidupan post larva udang windu. Pakan buatan dengan tambahan rekombinan hasil fusi protoplas intergenera $D$. salina dan $C$. vulgaris mengandung pigmen karotenoid lebih tinggi dari pakan yang lainnya pada penelitian ini, sehingga post larva udang yang mengkonsumsinya memiliki tingkat kelulushidupan lebih tinggi. Hal ini diduga bahwa kandungan pigmen karotenoid yang tinggi menunjang proses pergantian kulit, deposit materi dan sintesis pada penambahan jaringan, sebelum kulit udang yang baru mengeras. Penelitian tentang optimalisasi pertumbuhan dan pembuatan pakan telah dilakukan oleh Zainuri et al. (2003a) pada Phaffia rhodozyma untuk udang windu $(P$. monodon F.). Uji berupa penambahan konsentrasi pigmen selama lima minggu meningkatkan berat badan udang rata-rata sebesar $0,1 \mathrm{~g}$. Hasil tersebut diperkuat dengan peningkatan tingkat kelangsungan hidup yang mencapai $85 \%$.

\section{KESIMPULAN}

Berdasarkan hasil penelitian, maka dapat disimpulkan bahwa penambahan pakan kaya karotenoid dari rekombinan hasil fusi protoplas $D$. salina dan $C$. vulgaris mampu meningkatkan bobot tubuh dan kelulushidupan post larva udang windu (P. monodon F.). 
DAFTAR PUSTAKA

Abosereh, N.A., Mohamed H.A., and Abd ElChalk A.B. 2007. Genetic Construction of Potentially Probiotic Saccharomyces boulardii Yeast Strains Using Intraspesific Protoplast Fusion. Journal of applied Sciences Research. 3(3): 209-217.

Agustini, N.W.S. 2010. Kandungan Pigmen dan Asam Lemak Dunaliella salina pada Berbagai Penambahan Sumber Karbon. Seminar Nasional Biologi 2010. UGM, Jogjakarta.

Hersugondo, H.P. Kusumaningrum, \& M. Zainuri. 2010a. Application of Aquaculture Natural Food Produce by Protoplast Fusion Process of Dunaliella salina and Phaffia rhodozyma. Jurnal Ilmu Kelautan, 15 (4): 236-242.

2010b. Bussines Analysis for Improvement of Aquaculture Feed with Hight Carotenoid Content from Fusion Protoplasm of Algae Dunaliella and Khamir Phaffia rhodozyma to Increase Fishpond Income. Universitas Stikubank. Semarang.

Kementrian Kelautan dan Perikanan. 2011. Analisis Statistik Capaian Target Produksi Budidaya Perikanan Seluruh Provinsi. http://www.kkp.go.id/index.php/arsip/c/Ana lisis-Statistik-Capaian-Target-ProduksiSeluruh-Provinsi.htm/. Diakses pada 12 Desember 2011.

Kusumaningrum, H.P., E. Kusdiyantini, dan Wijanarka. 2003. Produksi Astaxanthin Phaffia rhodozyma melalui Teknik Fusi Protoplas. Laporan Penelitian Peningkatan
SDM, DIKTI. Universitas Diponegoro, Semarang

Mujiman, A. dan S. Suyanto. 2003. Budidaya Udang Windu. Penebar Swadaya. Jakarta

Zainuri, M, E. Kusdiyantini, Widjanarko, J. Soedarsono \& T. Yuwono. 2003a. Preliminary Study on the Use of Yeast Phaffia rhodozyma as pigment source on the Growth of Tiger Shrimp (Penaeus monodon Fabricius). Ilmu Kelautan 8 (1) : 47-52

Sedmak, J.J., D.K. Weerasinghe, and S.O. Jolly. 1990. Extraction and Quantitation of Astaxanthin from Phaffia rhodozyma. Biotechnology Techniques. 4(2): 107-112.

Sunaryo. 2000. Penggunaan Isochysis galbana sebagai Makanan Hidup Larva Udang Windu (Penaeus monodon F.) pada Stadia Zoea sampai dengan Mysis. FKIP UNDIP, Semarang , H.P. Kusumaningrum dan E.

Kusdiyantini. 2009. Pengembangan Produksi Karotenoid Alga Dunaliella dan Khamir Phaffia rhodozyma melalui Teknik Fusi Protoplasma untuk Diversifikasi Pakan Akuakultur. Laporan Penelitian Hibah Bersaing. Universitas Diponegoro, Semarang.

. 2003b. Study of Yeast Phaffia rhodozyma as Pigment Source to The Carotenoid Contents of Tiger Shrimp (Penaeus monodon Fabricius ). Ilmu Kelautan (2): $109-113$ 